\title{
Outcome of Dapsone in the Treatment of Ashy Dermatosis
}

\author{
Hossain $\mathrm{MS}^{1}$, Bhuian $\mathrm{I}^{2}$, Wahab A ${ }^{3}$, Khan $\mathrm{SA}^{4}$
}

\begin{abstract}
Background: Ashy dermatosis or Erythema Dyschromicum Perstans is a rare disorder of unknown etiology characterized by asymptomatic,slowly progressive, ashen-gray macular pigmentation of the skin. Various therapies have been tried without any benefit. The anti-inflammatory activity of dapsone on Erythema Dyschromicum Perstans may be the first oral treatment option. Objective: The aim of the present study was to evaluate the efficacy of dapsone in the treatment of ashy dermatosis. Methodology: This study was carried out on total thirty (30) cases having ashy dermatosis \& age group 20-60 years were selected for the study of which 16 females \& 14 males during the period of January 2010 to December 2011 in the Department of Dermatology \& Venereology of Shaheed Suhrawardy Medical College Hospital and Bangabandhu Sheikh Mujib Medical University at Dhaka city of Bangladesh. All the cases were diagnosed clinically \& confirmed by histopathological examination. The patients were given Dapsone $100 \mathrm{mg}$ daily for three months \& follow up was done for the next 3 months. Results: $16(53.33 \%)$ females \& 14(46.66\%) males were included in the study. Out of thirty patients, two patients $(6.66 \%)$ shown excellent response, seven patients $(23.33 \%)$ shown good response, eight $(26.66 \%)$ patients shown fair response, 8 patients (26.66\%) shown poor response \& remaining five patients $(16.66 \%)$ did not show any response clinically. So improvement was shown in $25(83.33 \%)$ cases and $5(16.66 \%)$ cases show no improvement at all. Conclusion: This study suggests that dapsone has significant efficacy profile for treatment option of ashy dermatosis.
\end{abstract}

Key words: Dapsone, Ashy dermatosis, outcome

\section{Introduction}

Ashy dermatosis or Erythema Dyschromicum Perstans (EDP) is an acquired generalized dermal hypermelanosis of unknown etiology ${ }^{1}$. The disease is characterized by hyperpigmented macules and patches of various shape and size with an ashen-grey to brown blue colour ${ }^{1,2}$. In the early stage they may have a thin very fine (several $\mathrm{mm}$ ) raised erythematous, non scaling border feeling like a cord ${ }^{2}$. This border later can be absent or mainly in darker skin types, evolve into a hypopigmented border that accentuates the hyperpigmentation ${ }^{1}$. The eruption can also be polymorphic, presenting simultaneously hypo- \& hyperpigmented macules ${ }^{1}$. It begins with disseminated macules which by peripheral extension \& coalescence to form large patches with a poly-cyclic outline ${ }^{3}$. The macules may at first be erythematous before assuming their characteristics bluish gray colour ${ }^{3}$. The disease progresses slowly over several years ${ }^{1}$. However, the discoloration persists usually without spontaneous regression ${ }^{1}$.
The most common areas of involvement are the trunk, arms, face, neck and proximal extremities ${ }^{1-5}$. Nail and mucous membrane involvement are not found ${ }^{2}$. The lesions are usually asymptomatic ${ }^{2,4,5}$. Slight pruritus can be reported ${ }^{1}$. It is a disease of young adult ${ }^{1}$, virtually always before 40 years ${ }^{2}$. There is no clear sexual predilection ${ }^{1,5}$. There is no genetic predisposition has been found ${ }^{5}$. Most patients with this disorder are Latin Americans ${ }^{3-6}$. A genetic susceptibility to develop the disease in Mexican Mestizo patients has been associated with the HLA-DR4, DRB1 0407 allele $^{3}$. All racial groups can be affected ${ }^{4}$.

The cause is unknown ${ }^{4-7}$. Though it has been associated with the ingestion of ammonium nitrate, exposure to environmental contaminant, pollutant, worm infestation, medication, possibility of endocrinopathy are some couse of $\mathrm{AD}^{5}$. Some authors state that Ashy dermatosis is a variant of lichen planus ${ }^{2}$. A limited number of cases were studied by immunofluorescence suggesting that this disorder may be related to lichen planus 5 . The most frequent causes of

1. Dr. Md. Shahadat Hossain, Assistant Professor, Department of Dermatology \& Venereology, Shaheed Suhrawardy Medical College \& Hospital, Dhaka

2. Dr. Israt Bhuian, Assistant Professor, Department of Dermatology \& Venereology, Shaheed Suhrawardy Medical College \& Hospital, Dhaka

3. Dr. Abdul Wahab, Associate Professor, Department of Dermatology \& Venereology, Bangabandhu Sheikh Mujib Medical University, Dhaka

4. Dr. Shafique Ahammed Khan, Medical Officer, Department of Dermatology, Shaheed Suhrawardy Medical College \& Hospital, Dhaka

\section{Correspondence}

Dr. Md. Shahadat Hossain, MBBS, DDV, FCPS, Assistant Professor, Department of Dermatology \&Venereology, Shaheed Suhrawardy Medical College \& Hospital, Sher-E-Bangla Nagar, Dhaka, Bangladesh; E-mail: dr.shahadat@hotmail.com; Mobile No: +8801819292667 
confusion with the following diseases like lichen planus pigmentosus, idiopathic eruptive macular pigmentation, late stage of Pinta, fixed drug eruption, confluent and reticulated papillomatosis (Gougerot and Carteaud), Addisions disease, haemochromatosis etc ${ }^{3-5,8}$. No definitive treatment of choice is presently available ${ }^{1,5}$.

A number of treatment modalities have been attempted, including sun protection, antibiotic, topical steroid, chemical peel, keratolytic agent, isoniazid, chloroquine, psychotherapy, but all with poor response ${ }^{5}$. Griseofulvin has been reported to induce complete resolution of the disease though the lesion to recur upon suspending treatment ${ }^{5}$. Some author suggested the therapeutic efficacy of clofazimine and dapsone on Erythema Dyschromicum Perstans (EDP) $)^{2,4-5,8-11}$. Besides its antimicrobial potency, it is effective in poly morphonuclear as well as lymphocytes rich dermatoses ${ }^{5,8}$. Dapsone possibly plays a role in the regulation of immune responses involved in the pathogenesis of Ashy dermatosis ${ }^{5,8}$. Nevertheless, more reports \& studies are necessary. The aim of this study was to evaluate the efficacy and safety of dapsone in the treatment of ashy dermatosis.

\section{Methodology}

This study was carried out for a period of two years from January 2010 to December 2011 in the Department of Dermatology \& Venereology at Shaheed Suhrawardy Medical College Hospital (ShSMCH) and Bangabandhu Sheikh Mujib Medical University (BSMMU), Dhaka. Total thirty patients of ashy dermatosis were selected considering exclusion criteria like patients with known hypersensitivity to any ingredients of the dapsone, pregnancy, lactation, impaired hepatic function, impaired renal function and severe systemic illness, any medication that interfere with dapsone. The inclusion criteria of patients selection were included both male \& female of young adult, patient willing to give consent to take part in the study, patient expected to be available for the duration of the study and able to comply with the study visit, Patients with ashy dermatosis diagnosed clinically and confirmed by histopathological examination and patients received no topical or systemic treatment for four weeks prior and during the protocol. Serum Glucose 6phosphate dehydrogenase level was done in each patient and was revealed normal. Skin biopsy from the affected area was taken in all cases for histopathological examination to confirm the diagnosis. Complete blood count with ESR, platelet count, urine for $\mathrm{M} / \mathrm{E}$, fasting blood sugar, liver function test (SGPT, SGOT), renal function test (serum creatinine), Glucose 6-phosphate dehydrogenase were done. The study group was treated with the dapsone $100 \mathrm{mg}$ (tab Anasone/ lepsone $100 \mathrm{mg}$ ) daily for three months. Dapsone may produce hematological, hepatic, gastrointestinal, neurological, psychiatric and hypersensitivity reaction. The clinical response and adverse effects of treatment were assessed in $1 \frac{1}{2}$ monthly follow up by clinical examination among all study people $(n=30)$. The clinical response of the treatment was measured (the hyperpiguented area) by taken photograph befoer \& after the treatment. Excellent response when $>75 \%$ improvement occur; good response when 50 $75 \%$ clearing of the lesion, fair $25-50 \%$ clearing and poor when $25 \%$ clearing of skin lesion occurred. After collection of data, they were screened by checking consistency, edited and were finally analyzed by software Statistical Package for Social Science (SPSS).

\section{Results}

The study was conducted on 30 patients of ashy dermatosis. Most the patient were in the age group of 36 to 40 years and the mean age $\pm \mathrm{SD}$ was $43.50 \pm 2.21$ years (Table 1 ).

Table 1: Distribution of the respondents by age $(n=30)$

\begin{tabular}{lcc}
\hline Age( years) & Frequency & Percentage \\
\hline $36-40$ & 10 & 33.33 \\
$41-45$ & 9 & 30.0 \\
$46-50$ & 9 & 30.0 \\
$51-55$ & 2 & 6.67 \\
Total & $\mathbf{3 0}$ & $\mathbf{1 0 0 . 0}$ \\
\hline
\end{tabular}

$*$ Mean $\pm \mathrm{SD}=43.50 \pm 2.21$

Female was predominant than male which was $16(53.3 \%)$ and $14(46.7 \%$ ) cases respectively (Table 2$)$.

Table 2: Distribution of the respondents by $\operatorname{sex}(n=30)$

\begin{tabular}{lccc}
\hline Sex & Frequency & Percentage & p value* \\
\hline Male & 14 & 46.7 & \\
Female & 16 & 53.3 & 0.465 \\
Total & $\mathbf{3 0}$ & $\mathbf{1 0 0 . 0}$ & \\
\hline
\end{tabular}

*Z-test was done to measure the level of significant.

The two samples was not significantly $(\mathrm{p}=0.465)$ different.

During study period there were no cases of haematological, hepatic, gastrointestinal, neurological, and psychiatric or hypersensitivity disorders found in 1 st follow up as well as 2nd follow up.

Table 3: Distribution of the respondents by site of involvement $(n=30)$

\begin{tabular}{lcc}
\hline Site & Frequency & Percentage \\
\hline Trunk & 11 & 36.7 \\
Neck & 09 & 30.0 \\
Upper extremity & 07 & 23.3 \\
Face & 03 & 10.0 \\
Total & $\mathbf{3 0}$ & $\mathbf{1 0 0 . 0}$ \\
\hline
\end{tabular}

The most common site of involvement of ashy dermatitis has been found in the trunk which was $11(36.7 \%)$ cases followed by neck and lower extremity which were $9(30.0 \%)$ cases and $7(23.3 \%$ ) cases respectively (Table 3$)$. The therapeutic response of ashy dermatosis among the patients was observed with a high response $(56.7 \%)$ than poor or no 
response $(43.3 \%)$ (Table 4).

Table 4: Therapeutic response of ashy dermatosis among the patients $(n=30)$

\begin{tabular}{lcc}
\hline Response & Frequency & Percentage \\
\hline Excellent & 02 & 6.7 \\
Good & 07 & 23.3 \\
Fair & 08 & 26.7 \\
Poor & 08 & 26.6 \\
No response & 05 & 16.7 \\
Total & $\mathbf{3 0}$ & $\mathbf{1 0 0 . 0}$ \\
\hline
\end{tabular}

The final outcome after therapy was compared with partial response $(83.3 \%)$ and no response $(16.7 \%)$ and was found a significant association $(\mathrm{p}=0.001)$ (Table 5).

Table 5: Final outcome of the patients after therapy $(n=30)$

\begin{tabular}{lccc}
\hline Response & Frequency & Percentage & p value \\
\hline Partial response & 25 & 83.3 & \\
No response & 05 & 16.7 & 0.001 \\
Total & $\mathbf{3 0}$ & $\mathbf{1 0 0 . 0}$ & \\
\hline
\end{tabular}

*Z-test was done to measure the level of significant. Percentage

of partial response was significantly $(\mathrm{p}<0.001)$ higher than in no response.

\section{Discussion}

Ashy dermatosis is a typically asymptomatic disease of unknown origin ${ }^{1}$. It causes eruption of oval, irregular or polycyclic, gray macules with erythematous, indurated inflammatory borders ${ }^{2}$.
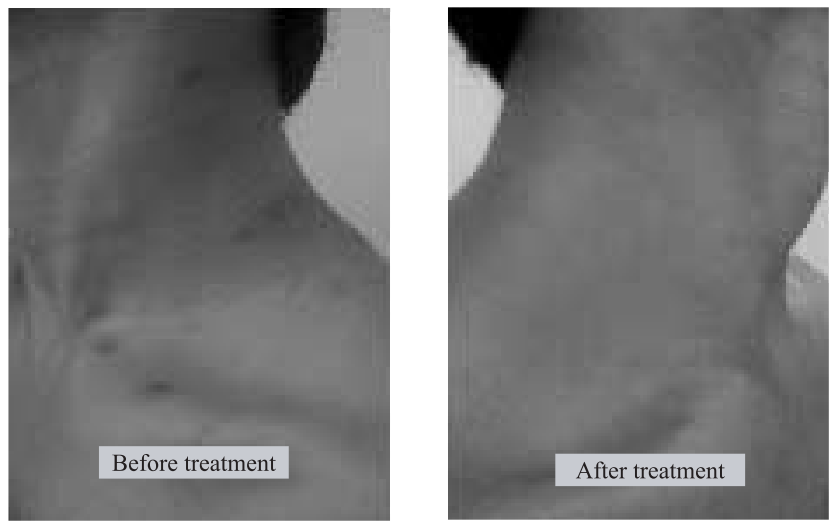

Fig 1: Multiple discrete hyper pigmented macules and patches on the side of neck

Site of involvements are trunk, extremities, face \& neck. It typically occurs symmetrically with progression loses their erythmatous border. There is no effective treatment for the disease $^{4}$. Therapeutic agents used for lichen planus may beneficial for the acute inflammatory stage, but have limited effect on the pigmented lesions.

No treatment of choice is presently available. Various therapies have been tried including sun protection, chemical peel, antibiotic, corticosteroid, vitamin, isoniazid, griseofulvin and chloroquine, without any benefit ${ }^{4}$. Some authors have suggested the therapeutic efficacy of clofazimine and dapsone on ashy dermatosis. No standardized methods exists for the evaluation of the severity of the disease $\&$ there are no consensual criteria of improvement or cure.
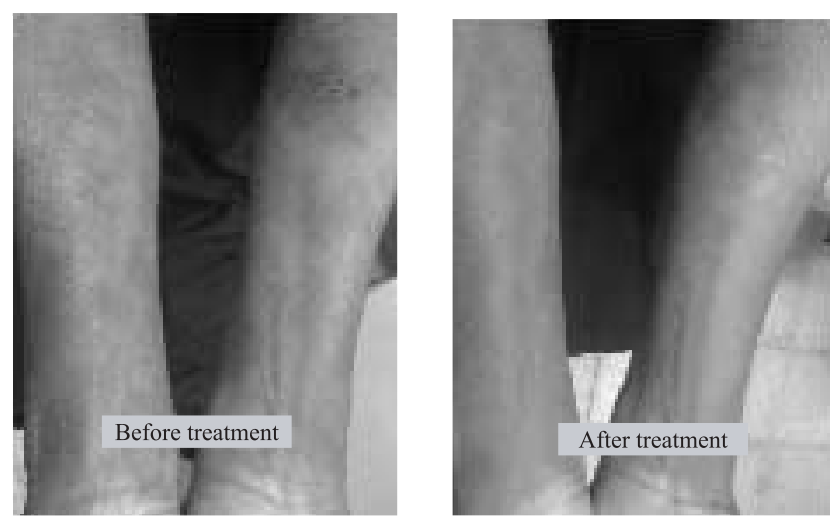

Fig 2: Multiple discrete hyper pigmented macules and patches on the of upper extremities

Total thirty patients were enrolled in this study. Out of all patients of this study maximum $33.3 \%$ were of $35-40$ years, followed by $30 \%$ of $40-45$ years and $45-50$ years. Only 7\% patients were more than 50 years of age. According to Lapeere et $\mathrm{al}^{1}$ it is a disease of young adults. According to James et $\mathrm{al}^{2}$ the age of onset is virtually always before 40 . Since it is a chronic disease, patients of all ages are seen. So these studies are nearly consistent with this study.

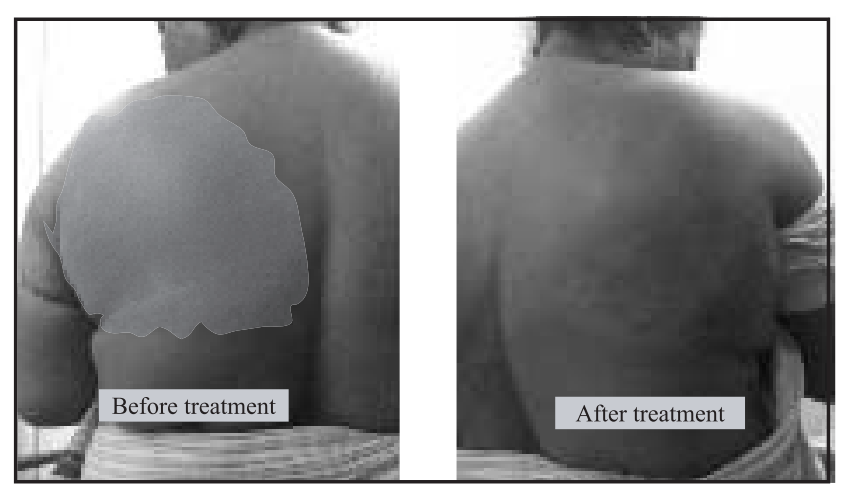

Fig 3: Diffuse hyper pigmented patches on back of a middle aged woman

In this study females were $53.3 \%$ and males were $46.7 \%$. According to Lapeere $^{1}$ et al there is no clear sexual predilection. According to Bahadir et $\mathrm{al}^{5}$ both sexes are equally affected. The finding of the present study is similar to other syudies.

In this study ashy dermatosis is very common in housewives $(50 \%)$, and service holder $(40 \%)$. This study also revealed that lower class $(53.3 \%)$ and middle class $(40 \%)$ 
respondents were mostly affected. So all of this revealed that underprivileged people were more attend in public hospital than high privileged people.
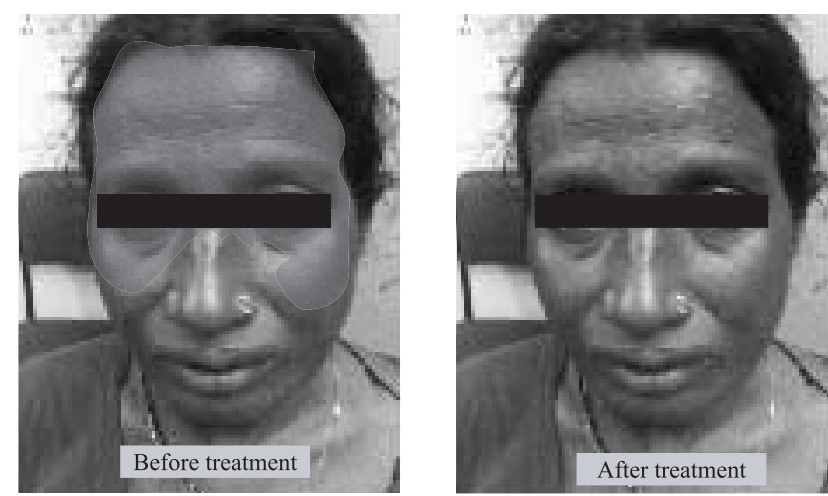

Fig 4: Diffuse hyper pigmented patches on both side of the face of a woman

Common sites of involvement ashy dermatosis in this series were trunk $(35 \%)$, neck (30\%), upper extremity $(25 \%)$, face $(10 \%)$. So this study is consistent with Bahadir et $\mathrm{al}^{5}$, Chun et $\mathrm{al}^{12}$, Roche et $\mathrm{al}^{13}$ and Brook et $\mathrm{al}^{14}$. Improvement was shown in 25 cases (83.3\%). 6.7\% had excellent response, $23.3 \%$ had good response, $26.7 \%$ had fair response, $26.7 \%$ had poor response.

According to Bahadir et $\mathrm{al}^{5}$ study on a single case report of erythema dyschromium pertstans and Kontochristopoulos et $\mathrm{al}^{8}$ study on two case of Erythema Dyschronicum perstans found that ashy dermatosis responded remarkably well to treatment with dapsone. So the present study is slightly differing from these studies.

Side effects noted through out the study were gastrointestinal (15\%) during the initial follow up visit which subsequently disappeared during the rest of the study period. Regarding adverse effects it was only mild gastrointestinal upset like nausea, vomiting, during the initial half of the study period which subsequently subsided. The study revealed that dapsone has remarkable efficacy profile for treatment option of ashy dermatosis.

The limitation of the study is that it is not a randomized control trial (RCT) thouth it is necessary to design study when an efficacy of the drug is evaluated. The reason of this is that there is no standard treatment for ashy dermatosis which is necessary to conduct a phase III trial to proof efficacy of a drug.

\section{Conclusion}

Dapsone is effective in the treatment of ashy Dermatosis. Clinical response is remarkable. However, large scale multicenter study should be conducted to prove the efficacy and safety of dapsone in the treatment of ashy Dermatosis. As majority of patients have shown certain amount of response at the end of 3 month treatment, study period may be extend for further few weeks. This was an open and uncontrolled study on a limited number of cases. Further blinded randomized placebo- controlled studies are needed to investigate the effectiveness of therapy.।

\section{References}

1. Lapeere H, Boon B, Schepper SD, Verhaeghe E, Ongenae K, Geel NV, Lambert J, Brochez L, Naeyaert JM. Hypomelanoses and hypermelanosesErythema dyschromicun perstans. Fitz Patrick's dermatology in general medicine Edn- 7th the Mc Graw Hill companies; 2008:640.

2. James WD, Berger TG, Elston D. Lichen planus and related conditionsErythema dyschromicum perstans. In Andrews Diseases of the Skin clinical dermatology. 10th edn. Saunders Elsevier; 2006; 224.

3. Mobini N, Toussaint S, Kamino H. Noninfectious Erythematous, Papular and Squamous diseases, Erythema Dyschromicum perstans. In levers Histopathology of the skin. 10th edn. Lippincott Williams and wilkins; 2009:172-3.

4. Soon C, Jones JB. Erythema Dyschromicum perstans. In treatment of Systemic disease. 3rd edn. Saunders Elsevier; 2010: 216

5. Bahadir S, Cobanoglu U, Cimsit G, Yayli S, Alpay K. Erythema Dyschromicum perstans: Response to dapsone therapy International Journal of Dermatology 2004:43:220-22

6. Molinero J, Vilata JJ, Nagore E, et al. Ashy dermatosis in an HIV antibody positive patient. Acta Derm Venereol 2000; 80: 78-79

7. Soto LD, Tomoko TH, Memije EV, et al. Pigmentary problems in the tropics Dermatol Cinics 1994; 12: 777-784.

8. Kontochristopoulos G, Stavropoulos P, Panteleos D, Aroni K. Erythema Dyschromicum perstans: Response to dapsone therapy. International Journal of dermatology 1998;37(10):796-98

9. Knox JM, Dodge BG, Freeman RG. Erythema Dyschromicum perstans. Arch dermatol 1968; 97: 262

10. Convit J, Kerdel-Vegas, F, Rodriguez G. Erythema Dyschromicum perstans: a hitherto undescribed skin disease. J Invest Dermatol 1961;36:457 462

11. Wozel, G and Barth, J. Current aspects of modes of action of dapsone. Int J Dermatol 1988;27:547 552

12. Chun JS, Hong S-K, Seo J-k, Lee D, Sung H-S, Hwang S-W, A Case of Unilateral Ashy Dermatosis. Ann Dermatol 2009;21(4):432434

13. Roche E, Febrer I, Alegre V. Persistant grayish pigmentation in a child. Actas Dermosifiliogr. 2007;98:59-60

14. Brook E, Tlougan MD et al. Erythema Dyschromicum perstans. Dermatology online Journal 2010;16(11):17 